\title{
The support of medication reviews in hospitalised patients using a clinical decision support system
}

\author{
Hugo A. J. M. de Wit ${ }^{*}$, Kim P. G. M. Hurkens², Carlota Mestres Gonzalvo ${ }^{3}$, Machiel Smid ${ }^{2}$, Walther Sipers², \\ Bjorn Winkens ${ }^{4}$, Wubbo J. Mulder ${ }^{5}$, Rob Janknegt ${ }^{3}$, Frans R. Verhey ${ }^{6}$, Paul-Hugo M. van der Kuy ${ }^{3}$ \\ and Jos M. G. A. Schols ${ }^{7}$
}

\begin{abstract}
Objectives: First, to estimate the added value of a clinical decision support system (CDSS) in the performance of medication reviews in hospitalised elderly. Second, to identify the limitations of the current CDSS by analysing generated drug-related problems (DRPs).

Methods: Medication reviews were performed in patients admitted to the geriatric ward of the Zuyderland medical centre. Additionally, electronically available patient information was introduced into a CDSS. The DRP notifications generated by the CDSS were compared with those found in the medication review. The DRP notifications were analysed to learn how to improve the CDSS.

Results: A total of 223 DRP strategies were identified during the medication reviews. The CDSS generated 70 clinically relevant DRP notifications. Of these DRP notifications, $63 \%$ (44) were also found during the medication reviews. The CDSS generated $10 \%$ (26) new DRP notifications and conveyed $28 \%$ (70) of all 249 clinically relevant DRPs that were found. Classification of the CDSS generated DRP notifications related to 'medication error type' revealed that 'contraindications/interactions/side effects' and 'indication without medication' were the main categories not identified during the manual medication review. The error types 'medication without indication', 'double medication', and 'wrong medication' were mostly not identified by the CDSS.
\end{abstract}

Conclusions: The CDSS used in this study is not yet sufficiently advanced to replace the manual medication review, though it does add value to the manual medication review. The strengths and weaknesses of the current CDSS can be determined according to the medication error types.

Keywords: Clinical decision support systems, Medication errors, Geriatrics

\section{Background}

Frailty in the aging patient is a state of vulnerability in which health status can suddenly decrease as a result of relatively small health events (Clegg et al. 2013). Ultimately frailty may lead to considerable disability. Frail elderly often have multiple chronic conditions which are associated with the use of many drugs. Polypharmacy

\footnotetext{
*Correspondence: h.dewit@zuyderland.nl

1 Department of Clinical Pharmacy and Toxicology, Zuyderland Medical Centre, Henri Dunantstraat 5, 6419 PC Heerlen, The Netherlands

Full list of author information is available at the end of the article
}

is often defined as the use of more than five drugs per patient. This is an arbitrarily chosen cut-off point and varies between studies. Alternatively, polypharmacy can be defined as the use of a higher number of drugs than clinically indicated (Maher et al. 2014; Hajjar et al. 2007). Both polypharmacy and frailty are independently associated with morbidity intensity suggesting a direct effect of polypharmacy on a patient's frailty status. The influence of polypharmacy on frailty might be explained by decreased compliance, more adverse drug reactions (ADR), and drug interactions. Excessive polypharmacy, 
which is the use of more than ten drugs, is an independent risk factor for mortality (Herr et al. 2015).

A drug-related problem (DRP) is "an event or a circumstance involving drug therapy that actually or potentially interferes with health care outcome" (Silva et al. 2015). DRPs are associated with (frail) elderly as a consequence of polypharmacy, complex dosing regimens as well as alterations in pharmacokinetics and pharmacodynamics. DRPs are also associated with cognitive and functional status (Silva et al. 2015).

Leendertse et al. showed that polypharmacy is an independent risk factor for hospitalisation. Of the unplanned hospital admissions $5.6 \%$ were medication-related. Of these almost half were probably preventable (Leendertse et al. 2008). Paradoxically, polypharmacy has been shown to increase during hospitalisation of elderly (Nobili et al. 2011).

\section{Medication review}

A medication review is defined as a structured evaluation of a patient's medication by a physician and a pharmacist, taking into account medical history and laboratory values. The medication review aims to reach agreement about drug therapy in order to optimise the impact of medication while minimising the number of medication-related problems. When the patient's input into the medication review is included with all available patient's information, the review is defined as a clinical medication review. Without the patient's input, the review is defined as a treatment review. This is often the case in hospitalised patients (Blenkinsopp et al. 2012; van Dijk et al. 2009). It has been suggested that there should be an intermediate definition for hospitalised patients, since patients are followed up daily by nursing staff and physicians, while recognising that dementing or very ill patients cannot give comments on their medication (van Dijk et al. 2009). In a systematic review by Christensen et al. no conclusive benefits on future hospitalisations or mortality in hospitalised patients are shown when performing medication reviews. However, performing medication reviews has shown to reduce the number of emergency department contacts (Christensen and Lundh 2013). Furthermore, it has been shown that regular revision of medication reduces DRPs and improves medication appropriateness (Alldred et al. 2013). The inconsistency of proven benefits of medication reviews might be caused by implementation problems. These problems involve the time efficiency of performing medication reviews as well as the structure and information used in a medication review. The output consistency of the health care professionals performing the medication reviews can also be a factor (de Wit et al. 2014b; Hurkens et al. 2013; Mestres Gonzalvo et al. 2015). These problems might be (partially) resolved by automation of the medication review (de Wit et al. 2013).

\section{Clinical decision support systems (CDSS)}

The Dutch Healthcare Inspectorate (IGZ) requires physicians to prescribe exclusively using computerised physician order entry (CPOE) systems with an integrated drug safety alert system.

In the Netherlands, a nationwide drug database is maintained by the Royal Dutch Association for the Advancement of Pharmacy (KNMP) that generates drug safety alerts to ensure medication surveillance which include dosage appropriateness, double medication, drug-drug interactions, and drug contraindications (Richtlijn elektronisch voorschrijven 2013). The pharmacist responsible for the CPOE can regulate the drug safety alerts to a degree (Eppenga et al. 2012). These alerts result from relatively uncomplicated algorithms that form a basic clinical decision support system (CDSS) (Kuperman et al. 2007). The use of a CDSS with advanced algorithms that combine medication and laboratory values is becoming common practice in the Netherlands, and the use of advanced algorithms that incorporate guidelines and drug-disease interactions that initiate treatment to prevent adverse drug events is up-coming (Rommers et al. 2011; O'Sullivan et al. 2014; Meulendijk et al. 2015). Unlike the basic algorithms that are routinely integrated into CPOEs, the advanced algorithms are mostly not integrated into a CPOE. Integration of a CDSS into a CPOE results in the presentation of alerts when a physician is prescribing medication. In this way the physician can adjust the prescription during the prescription process if necessary, instead of adjusting the prescription afterwards, such as when it is initiated by an alert from a stand-alone CDSS (de Wit et al. 2015; Eppenga et al. 2012; Tawadrous et al. 2011). Patient outcome benefits of using advanced CDSSs remain limited, but several studies do report positive results related to prevention of adverse drug events (Rommers et al. 2011; Tawadrous et al. 2011; Bright et al. 2012; Jaspers et al. 2011). Bright et al. (2012) have shown in a systematic review that CDSSs do influence "health care process measures' by improving the initiated treatment or preventive care in terms of: pharmacotherapy, laboratory test ordering, and chronic disease management.

In a recent study, the use of an advanced CDSS to support medication reviews in older hospitalised patients has shown to improve the appropriateness and accuracy of medication regimens (O'Sullivan et al. 2014).

The department of clinical pharmacy and toxicology of the Zuyderland medical centre has developed an advanced CDSS based on our experience with a simpler access based CDSS (de Wit et al. 2015). The currently 
developed advanced CDSS consists of algorithms that alert for the inappropriate combination of medication and laboratory values, for lack of guideline implementation, and gives suggestions to prevent adverse drug events as a result of drug-disease interactions. The development phases of the CDSS have been described in more detail previously (de Wit et al. 2013). The content development team consisted of several hospital pharmacists and internists, a neuropsychiatrist, and a nursing home physician. In the Netherlands, nursing home medicine is an officially recognised medical discipline for physicians attending nursing homes (Schols et al. 2004). The content was based on national guidelines, protocols and relevant studies. The CDSS consists of 469 clinical rules aiming to have a high sensitivity and specificity. This standalone CDSS has been developed to support medication reviews in synergy with the already integrated CPOE drug safety alerts that consider dosage appropriateness, double medication, drug-drug interactions, and drug contraindications.

The aim of this study was to estimate the value of this CDSS regarding the performance of medication reviews in hospitalised elderly by comparing DRPs taken from a multidisciplinary treatment review to the DRP notifications prompted by the CDSS. Furthermore, we aimed to identify the limitations of the current CDSS by analysing the CDSS generated DRP notifications.

\section{Methods}

From November 2012 to December 2013 medication reviews were performed in clinical patients admitted to the geriatric ward of the Zuyderland medical centre, located in Sittard-Geleen. The medication reviews were performed during the weekly 'gerontopharmacology meeting. During every gerontopharmacology meeting one patient was discussed for $0.5-1 \mathrm{~h}$. The patients were selected by the geriatrician and communicated to all the participants before the meeting. At least one geriatrician (leading practitioner and chairman of the meeting), one resident and one hospital pharmacist (in training) attended the meeting. In most cases, more clinicians attended, including geriatricians, residents, nurse practitioners and medical students. The meeting was also intended to provide educational value. The leading practitioner and chairman of the meeting was either a geriatrician or an internist, with a subspecialty in old age medicine. Both are geriatric experts, and have expertise in medical education. The attending hospital pharmacist had extensive experience in performing structured medication reviews, as necessary for this study. Apart from these experts, up to 5 postgraduate physician residents and 5 medical students attended the meeting.
The structure of the review was based on the method used in the PHARM-study and was followed during the medication reviews (Leendertse et al. 2011). This structure was: (1) Matching the prescribed medication with the known indications, (2) Matching indications with prescribed medications, (3) Relating the laboratory values to the prescribed medication, (4) A general discussion whether there were other suggestions based on the patients' or nurses input. Although the pharmacist did not perform patients' interviews, the geriatrician and residents had daily contact with the reviewed patients, and any relevant information was then presented in the meeting. The indirect input of patients' comments causes these medication reviews to supersede the requirements of a standard "treatment review", but does not meet the requirements of a "clinical medication review". For this study, we will continue to address them as medication reviews.

The hospital pharmacist prepared the medication review by documenting the DRP suggestions resulting from the manual check of medications, laboratory values, and other relevant clinical patient information. These suggestions were discussed during the medication review by the attendants. If they were accepted by the attendants as a DRP, it was included as a strategy to improve the patient's therapy. The accepted 'DRP strategies' were documented by the hospital pharmacist. A week after the medication review the hospital pharmacist documented which DRPs had indeed been executed. In this study, we will discuss the DRPs using the following terms: "DRP suggestions" (when DRPs were identified during the pharmacist's preparation), "DRP remarks" (newly introduced DRPs during the medication review), "DRP strategies" (when DRPs were accepted as therapy strategies for the patient during the medication review), "DRP notifications" (the DRPs found by the CDSS), and "DRPs executed" (the carried out therapy strategies based on the DRP strategies).

In addition, prior to the gerontopharmacology meeting the hospital pharmacist extracted all electronic available patient information: laboratory values, medication, and documented indications and contraindications. The extracted electronic patient information was introduced into the CDSS in April 2015, therefore it was not possible that the medication reviews identified DRPs were influenced by the CDSS generated DRPs. The CDSS is designed to exclusively alert for relevant DRPs (DRP notifications). This is done by including 'triggers' that allow assessing whether the predefined DRPs are relevant or non-relevant. For example, there is an algorithm alerting for the prescription of a gastrointestinal prophylaxis in a patient at risk. However, for some patients a prophylaxis will already be prescribed and this notification is 
therefore assessed as a non-relevant notification by the CDSS. The DRP notifications from the CDSS were independently checked for relevancy and classified for type of medication error by hospital pharmacist HW and geriatrician KM. In case of disagreement, consensus was obtained by discussing on a case by case basis.

The local Medical Research \& Ethics Committee (MREC) determined this study to be non-accessory for the Dutch Medical Research in Human Subjects Act (non-WMO).

Numerical variables were presented by mean (SD; range, i.e. minimum-maximum value) and categorical ones by number (\%). The descriptive statistics were computed using Microsoft Excel 2010.

\section{Results}

We held 33 documented gerontopharmacology meetings during which 33 medication reviews were performed, all on different patients. The mean age of the reviewed patients was 83 years (SD 8.0; range 69-97). Gender was distributed almost equally with $55 \%(n=18)$ of the patients being male. The mean amount of prescribed drugs per patient was 15.2 (SD 4.0; range 8-27 medicines).

\section{Drug-related problems}

The pharmacist who prepared the gerontopharmacology meeting had a total of 221 DRP suggestions based on the 33 medication reviews. Of these 221 DRP suggestions, 166 DRP suggestions were accepted as DRP strategies, while 55 DRP suggestions were rejected and an additional 57 DRP remarks were introduced during the meeting and accepted as DRP strategies. Thus, a total of 223 DRP strategies were accepted with a mean of 7.0 (SD 2.2; range 2-11) per patient (see Fig. 1).

The CDSS generated 574 DRP notifications. Of these notifications the CDSS determined 516 to be non-relevant notifications. The remaining 58 DRP notifications were determined as relevant DRP notifications by the CDSS. These 58 CDSS DRP notifications were checked by HW and KM, 51 of which were considered clinically relevant for the patient. In addition, HW and KM confirmed 19 notifications that were assessed as nonrelevant by the CDSS to be clinically relevant DRP notifications. In total 70 DRP notifications issued by the CDSS were relevant (see Fig. 1).

Of the confirmed relevant CDSS DRP notifications, $63 \%$ (44) DRP notifications were also noted and accepted as DRP strategies in the medication reviews. Twenty-six DRP notifications from the CDSS had not been identified during the medication review but were assessed as clinically relevant by HW and KM. Table 1 shows the CDSS
DRP notifications that went unnoticed in the medication reviews.

These 44 DRP notifications covered $20 \%$ of the DRP strategies identified in the medication review. The CDSS generated an additional 26 newly confirmed DRP strategies (see Fig. 1). The 223 DRP strategies from the medication reviews combined with the additional 26 confirmed relevant DRP notifications from the CDSS, add up to a total of 249 DRP strategies. The CDSS generated $28.1 \%$ (70) of all 249 DRPs strategies of which $10 \%$ (26) were new notifications.

The 223 DRP strategies determined in the medication reviews were followed up for implementation a week after the medication review. Fifty-five percent (121) of these DRP strategies were executed a week after the medication review, which is a mean 3.8 (SD 2.3; range 0-9) DRPs executed per patient.

\section{Classification of drug-related problems}

All DRPs were categorised according to a seven-fold 'medication error type' classification (see Table 2). Table 2 shows that two medication error types (a) indication without medication' and (b) 'medication without indication' made up more than half of the existing medication errors. The 26 relevant DRP notifications not recognised during the medication reviews were mainly medication errors type (c) 'contraindications/interactions/side effects' and error type (a) 'indication without medication'. The error types (b) 'medication without indication', (e) 'double medication', and (f) 'wrong medication' were least likely to be identified by the CDSS.

\section{CDSS efficiency}

The efficiency of the CDSS was determined by calculating the sensitivity and specificity of the CDSS using the confirmed correctness of CDSS notifications. Fifty-one of the 58 DRP notifications were found true positive, giving a sensitivity of $72.9 \%$. Of the 516 DRPs assessed as nonrelevant notifications by the CDSS, 19 notifications were confirmed relevant by $\mathrm{KH}$ and HW giving 497 DRP true negative notifications resulting in a specificity of $98.6 \%$. In Table 3 the sensitivity and specificity are shown.

The confirmed clinically relevant CDSS notifications were analysed to determine the reasons why they were incorrectly assessed as relevant or irrelevant by the CDSS. In Table 4, the CDSS notifications assessed as non-relevant but confirmed as relevant are shown. In Table 5, the CDSS notifications assessed as relevant but confirmed as non-relevant are shown. The actions needed to improve the sensitivity and specificity of these algorithms varies considerably and are also shown in Tables 4 and 5 . 


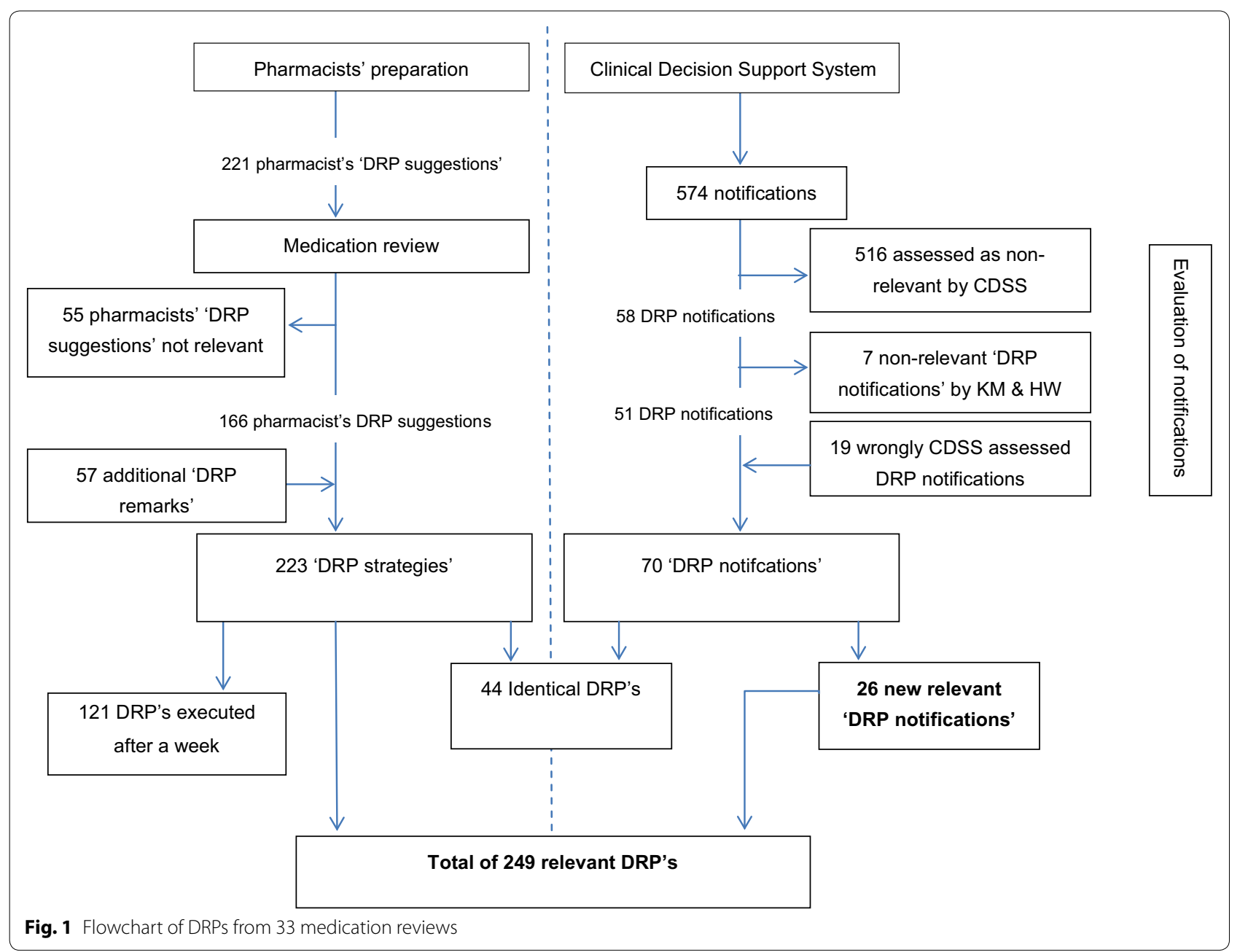

\section{Discussion}

This study shows that performing medication reviews in a hospitalised geriatric patient group can be of value when considering the mean of 7.0 (SD 2.2) DRP strategies identified during the gerontopharmacology meetings. The acceptance rate of the pharmacists suggestions was $74.4 \%$ (166 out of 221 DRP suggestions) which corresponds with other described acceptance rates of DRP suggestions ranging from 39.0 to $91.6 \%$ in long-term care patients and $65 \%$ in hospitalised patients (Verrue et al. 2009; Mestres et al. 2015; van Dijk et al. 2009). In our study, we also investigated to which extend the DRP strategies were executed by the physician 1 week after the medication reviews. This resulted in $54.3 \%$ (122) executed DRPs after 1 week. Another study reports that $65 \%$ of the DRP strategies were executed (van Dijk et al. 2009). It should be mentioned that the patient group studied is easily susceptible to clinical changes, which might explain why physicians decided not to execute certain DRP strategies.

\section{CDSS supports medication review}

Despite the absence of conclusive benefits for morbidity and mortality, medication reviews feature prominently in pharmacists' and physicians' daily work (Hurkens et al. 2013; de Wit et al. 2014b; Wallerstedt et al. 2014; Christensen and Lundh 2013). Many other studies have shown improvement of medication safety in elderly with the support of a CDSS (Marasinghe 2015; Ranji et al. 2014). Whether a CDSS can support the manual medication review can be shown by comparing the confirmed DRP notifications with the DRP strategies of the medication reviews. This study shows that $20 \%$ of the DRP strategies were also identified by the CDSS. Furthermore, the CDSS identified 26 DRPs that were overlooked in the manual medication review showing that the CDSS adds value to performing the medication review manually. Meulendijk et al. (2015) also suggested that a CDSS may improve medication review effectiveness. However, the results also show the CDSS can be improved in efficiency and content. 
Table 1 DRP notifications not identified in the medication review

Potassium level_drugs inducing hypokalemia

Use of aspirin, dipyridamol, clopidogrel, prasugrel without a statin

Calcium channel blockers with chronic constipation

Atypical antipsychotics combined with oral blood glucose lowering

drugs or insulin

Atypical antipsychotics combined with Alzheimer medication

Nitrate without aspirin or clopidogrel, prasugrel, ticagrelor

Metformin with unknown vitamin B12 level

Renal failure with amoxicillin (oral)

Atypical antipsychotics combined with antihypertensive medication

Nitrate without a beta blocker

Nortriptyline usage in elderly patients

Tricyclic antidepressants with constipation

Paracetamol in elderly patients in combination with risk factors

Gastric protection without prophylaxis

Gastric protection, prophylaxis dosage not high enough

Classical antipsychotics with anticholinergic effects-start alpha blockers may be related to this effect

Tricyclic antidepressants with cardiac conductive abnormalities

Use of rheumatoid arthritis drugs without a statin

Bisphosphonates, calcium and vitamin D supplementation: suggest prescribing calcium

Renal failure with metoclopramide

\section{CDSSs strengths and weaknesses}

The classification of types of medication errors shows that the notifications prompted by the CDSS, which went unrecognised during the medication reviews are strongly represented by the medication error types (c) 'contraindications/interactions/side effects' and error type (a) 'indication without medication'. The importance in recognising these medication error types has also been shown by Leendertse et al. in the evaluation of the potential causes of the preventable medication-related hospital admissions. Their evaluation showed a variety of a number of potential causes like gastrointestinal problems such as bleeding and constipation and cardiovascular problems such as heart failure (Leendertse et al. 2008). These cases also involved the medication error types (a) 'indication without medication', and (c) 'contraindications/interactions/side effects', mostly missed in the medication review but recognised by the CDSS.

The medication error types (b) 'medication without indication', (e) 'double medication', and (f) 'wrong medication' were frequently not identified by our CDSS. Depending on the medication error type, it can be reasoned why the CDSS did not find these types of errors. The medication error type (b) requires the input of the 'indication'. In the included medication reviews only three indications for all patients where documented in the CPOE and therefore available for the CDSS. It has already been suggested that multi-morbidity from electronic health records is poorly adopted by currents CDSSs (Fraccaro et al. 2015). The reason why the medication error types (e) 'double medication' and (f) 'wrong medication' were not found by the CDSS is because these DRPs are not included in the algorithms. These DRPs are routinely screened by the physician and pharmacist in the CPOE integrated G-standard. Our CDSS has been developed to have new notifications in addition to the CPOE notifications. The appearance of the many medication

Table 2 Classification of medication error types

\begin{tabular}{|c|c|c|c|c|c|c|c|}
\hline & Type of error & $\begin{array}{l}\text { All remarks } \\
=308\end{array}$ & $\begin{array}{l}\text { Notifica- } \\
\text { tions CDSS } \\
\text { and review = } 249\end{array}$ & $\begin{array}{l}\text { CDSS } \\
\text { total }=70\end{array}$ & $\begin{array}{l}\text { Review } \\
\text { total }=223\end{array}$ & $\begin{array}{l}\text { CDSS new } \\
\text { notifications } \\
\mathrm{N}=26\end{array}$ & $\begin{array}{l}\text { No notifications } \\
\text { in CDSS as \% } \\
\text { of review remarks } \\
(n=179 \text { vs. } \\
n=223)\end{array}$ \\
\hline a & $\begin{array}{l}\text { Indication without } \\
\text { medication }\end{array}$ & $94(30.5 \%)$ & $76(30.5 \%)$ & $29(41 \%)$ & $68(30.5 \%)$ & $8(31 \%)$ & 47 (69.1\%) \\
\hline$b$ & $\begin{array}{l}\text { Medication with- } \\
\text { out indication }\end{array}$ & $78(25.3 \%)$ & $66(26.5 \%)$ & $2(3 \%)$ & $66(29.6 \%)$ & 0 & $64(97.0 \%)$ \\
\hline c & $\begin{array}{l}\text { Contraindications/ } \\
\text { interactions/side } \\
\text { effects }\end{array}$ & $32(10.4 \%)$ & $25(10.0 \%)$ & $20(29 \%)$ & $11(4.9 \%)$ & $14(54 \%)$ & $5(45.5 \%)$ \\
\hline d & Dosage problems & $42(13.6 \%)$ & $35(14.1 \%)$ & $14(20 \%)$ & $31(13.9 \%)$ & $4(15 \%)$ & $21(67.7 \%)$ \\
\hline e & Double medication & 10 (3.2\%) & 7 (2.8\%) & 0 & 7 (3.1\%) & 0 & 7 (100 \%) \\
\hline f & Wrong medication & $26(8.4 \%)$ & $22(8.8 \%)$ & $1(1 \%)$ & $22(9.9 \%)$ & 0 & $21(95.5 \%)$ \\
\hline g & $\begin{array}{l}\text { Therapeutic drug } \\
\text { monitoring }\end{array}$ & $26(8.4 \%)$ & $18(7.2 \%)$ & $4(6 \%)$ & $18(8.1 \%)$ & 0 & $14(77.8 \%)$ \\
\hline
\end{tabular}

The columns shows type of medication errors identified during the medication review and by our CDSS independently of the medication review. The last column shows the percentage of medication error types our CDSS did not identify 
Table 3 Sensitivity $=$ A/A $+C \times 100 \%=72.9 \%$, specificity $=D / D+B \times 100=98.6 \%$

\begin{tabular}{llll}
\hline & $\begin{array}{l}\text { Confirmed } \\
\text { relevant DRPs }\end{array}$ & $\begin{array}{l}\text { Confirmed irrel- } \\
\text { evant DRPs }\end{array}$ & \\
\hline $\begin{array}{c}\text { Relevant DRP } \\
\text { notifications }\end{array}$ & $51(\mathrm{~A})$ & 7 (B) & $58(\mathrm{~A}+\mathrm{B})$ \\
$\begin{array}{c}\text { Non-relevant DRP } \\
\text { notifications }\end{array}$ & $19(\mathrm{C})$ & $497(\mathrm{D})$ & $516(\mathrm{C}+\mathrm{D})$ \\
& $70(\mathrm{~A}+\mathrm{C})$ & $504(\mathrm{~B}+\mathrm{D})$ & $\mathrm{N}=574$ \\
\hline
\end{tabular}

error types (e) 'double medication' and (f) 'wrong medication', suggests there is a high degree of alert fatigue with regard to CPOE alerts. Alert fatigue occurs when there are a high number of non-clinically relevant alerts, which results in the overlooking of both relevant and not-relevant alerts (van der Sijs et al. 2006). The CPOE integrated G-standard has been reported to generate $5.8 \%$ relevant drug safety alerts (Eppenga et al. 2012). The efficiency of our CDSS is much higher with a sensitivity of $72.9 \%$ and a specificity of $98.6 \%$. The analysis of why the CDSS assessed DRP notifications as non-relevant or relevant, while later evaluated as relevant and non-relevant respectively, can be used to increase the efficiency of the CDSS.

\section{Limitations of the study}

We attempted to estimate the added value of the developed CDSS and the effectiveness of the manual medication review. Our study was limited, however, to the performed medication reviews, the CDSS-generated DRP notifications and the DRPs executed within a week after the medication review. An analysis of why DRP strategies were not executed would perhaps have provided interesting insights into the execution part of the medication review process. Furthermore, all DRPs were classified according to the type of medication error observed. A few DRPs, however, involved consultations with other physicians concerning the use of certain drugs

\section{Table 4 CDSS notifications assessed as non-relevant but confirmed as relevant}

\begin{tabular}{|c|c|c|}
\hline DRP notifications & $\begin{array}{l}\text { DRP strategy in handmade } \\
\text { medication review }\end{array}$ & $\begin{array}{l}\text { Reason assessed as non-relevant notification and } \\
\text { improvement suggestion }\end{array}$ \\
\hline $\begin{array}{l}\text { Potassium levels_-drugs inducing } \\
\text { hyperkalemia }\end{array}$ & $\begin{array}{l}\text { Stop potassium supplement with potas- } \\
\text { sium level of } 3.9\end{array}$ & $\begin{array}{l}\text { Cut-off point for potassium (>5.5 mmol/l) was not reached. Cut- } \\
\text { off point needs to be refined }\end{array}$ \\
\hline Benzodiazepines and fall risk & $\begin{array}{l}\text { Stop or dose benzodiazepine 'as needed' } \\
\text { Phase out benzodiazepine }\end{array}$ & $\begin{array}{l}\text { Benzodiazepine usage should be stopped or reassessed when } \\
\text { chronic } \\
\text { A predictive risk algorithm for falling might be developed }\end{array}$ \\
\hline $\begin{array}{l}\text { Paracetamol in elderly patients in combi- } \\
\text { nation with risk factors }\end{array}$ & $\begin{array}{l}\text { Stop paracetamol because of medica- } \\
\text { tion induced headaches }\end{array}$ & $\begin{array}{l}\text { Include code of International Statistical Classification of Diseases } \\
\text { into algorithm }\end{array}$ \\
\hline $\begin{array}{l}\text { Nortriptyline in elderly: the maximum } \\
\text { daily dose in elderly is } 50 \text { mg. If nor- } \\
\text { triptyline is dosed higher, an ECG and } \\
\text { monitoring of nortriptyline levels is } \\
\text { recommended }\end{array}$ & No strategy & $\begin{array}{l}\text { Two separate prescriptions of nortriptyline: } 10 \mathrm{mg} \text { and } 50 \mathrm{mg} \text {. The } \\
\text { two prescriptions should be combined by the CDSS to show the } \\
\text { total dosage }\end{array}$ \\
\hline $\begin{array}{l}\text { Paracetamol in elderly in combination } \\
\text { with risk factors }\end{array}$ & $\begin{array}{l}\text { Chronic use of paracetamol should be } \\
\text { reduced to a maximum of } 3 \mathrm{~g} \text { daily }\end{array}$ & $\begin{array}{l}\text { Chronic paracetamol usage in higher dosages should be avoided. } \\
\text { Additional risk factors should be included in the algorithm } \\
\text { alongside the dosage }\end{array}$ \\
\hline $\begin{array}{l}\text { Renal Failure and Amoxicillin/Clavulanic } \\
\text { acid (oral) }\end{array}$ & $\begin{array}{l}\text { Renal function } 32 \mathrm{ml} / \mathrm{min} \text { and oral } \\
\text { dosage amoxicillin/clavulanic acid } \\
\text { increased }\end{array}$ & $\begin{array}{l}\text { Too low dosages when renal function improves should be } \\
\text { included in the algorithm }\end{array}$ \\
\hline $\begin{array}{l}\text { Alendronic acid usage longer than } \\
5 \text { years }\end{array}$ & $\begin{array}{l}\text { Consider whether continuation after } \\
5 \text { years of use is necessary }\end{array}$ & $\begin{array}{l}\text { The original prescription starting date was not taken into account } \\
\text { when patient was admitted to hospital }\end{array}$ \\
\hline Citalopram in elderly & $\begin{array}{l}\text { Prescribed dosage } 30 \mathrm{mg} \text {, maximum } \\
\text { dosage in elderly } 20 \mathrm{mg}\end{array}$ & $\begin{array}{l}\text { Two separate prescriptions citalopram; } 10 \text { and } 20 \mathrm{mg} \text {. The two } \\
\text { prescriptions should be combined by the CDSS in order to the } \\
\text { total dosage }\end{array}$ \\
\hline Anticoagulation therapy and INR & Increase dosage since INR is too low & $\begin{array}{l}\text { The upper limit cut-off point for }>5.5 \text { INR was not reached. The } \\
\text { algorithm focusses on toxicity, while for medication reviews } \\
\text { a lower limit should also be included to monitor therapeutic } \\
\text { efficacy }\end{array}$ \\
\hline $\begin{array}{l}\text { Potassium levels_-drugs inducing } \\
\text { hyperkalemia }\end{array}$ & $\begin{array}{l}\text { Elevated potassium level of } 4.6 \text { with } \\
\text { Losartan (which contains potassium). } \\
\text { Converted to another ATIl-antagonist }\end{array}$ & $\begin{array}{l}\text { Cut-off point is set to trigger when potassium }>5.5 \mathrm{mmol} / \mathrm{l} \text {. The } \\
\text { specific prescription of losartan is not included in the algorithm } \\
\text { of drugs containing potassium }\end{array}$ \\
\hline $\begin{array}{l}\text { Opioids without laxative agents. Up to } \\
70 \% \text { of the patients using opioids } \\
\text { experience opioid-induced constipa- } \\
\text { tion }\end{array}$ & $\begin{array}{l}\text { Restart laxative agents when diarrhea } \\
\text { has stopped }\end{array}$ & $\begin{array}{l}\text { Prescription of laxative agents is temporarily stopped, but remains } \\
\text { in the medication extraction. } \\
\text { Temporarily stopped drugs should not be included in extraction. } \\
\text { An indicator for bowel movement (stool) might be introduced }\end{array}$ \\
\hline
\end{tabular}


Table 5 CDSS notifications assessed as relevant but confirmed as non-relevant

\begin{tabular}{|c|c|c|}
\hline DRP notifications & Reason scored as non-relevant & Action needed to improve algorithm \\
\hline $\begin{array}{l}\text { Renal failure and Rosuvastatin: contra- } \\
\text { indicated in renal failure }\end{array}$ & $\begin{array}{l}\text { Renal function was } 14 \mathrm{ml} / \mathrm{min} \text { with a } \\
\text { daily dose of } 10 \mathrm{mg} \text { Rosuvastatin, } \\
\text { which is acceptable when the dosage } \\
\text { is slowly increased }\end{array}$ & $\begin{array}{l}\text { Introduce Rosuvastatin dosage limits of renal dysfunction into the } \\
\text { algorithm as well as start date of prescription }\end{array}$ \\
\hline $\begin{array}{l}\text { Metformin and unknown vitamin B12 } \\
\text { level }\end{array}$ & $\begin{array}{l}\text { Vitamin B complex is prescribed. Vitamin } \\
\text { B12 levels are regarded as irrelevant } \\
\text { when supplemented }\end{array}$ & $\begin{array}{l}\text { Prescription of vitamin B complex should be included in the } \\
\text { algorithm. Furthermore, determined vitamin B12 levels should } \\
\text { also be included in the algorithm }\end{array}$ \\
\hline $\begin{array}{l}\text { Tramadol and seizure: Tramadol should } \\
\text { be used with caution in patients with } \\
\text { a history of epilepsy and those on con- } \\
\text { comitant seizure threshold-lowering } \\
\text { medication. Consider switching to } \\
\text { other pain medication }\end{array}$ & $\begin{array}{l}\text { Tramadol is contraindicated in epilepsy, } \\
\text { associated drugs (nortriptyline) is } \\
\text { prescribed for depression }\end{array}$ & $\begin{array}{l}\text { Nortriptyline should be removed from the algorithm since this is } \\
\text { not a standard therapy for epilepsy }\end{array}$ \\
\hline $\begin{array}{l}\text { Renal Failure and pregabalin: initial } \\
\text { dose } 75 \text { mg per day, maximum dose } \\
300 \text { mg per day }\end{array}$ & $\begin{array}{l}\text { Renal function of } 43 \mathrm{ml} / \mathrm{min} \text { with a dos- } \\
\text { age of } 150 \mathrm{mg} \text { daily. Maximum dose } \\
\text { was not exceeded }\end{array}$ & $\begin{array}{l}\text { The algorithm should be adjusted to take into account the start- } \\
\text { ing date of the prescription }\end{array}$ \\
\hline $\begin{array}{l}\text { Anticoagulation therapy and INR: aceno- } \\
\text { coumarol }\end{array}$ & $\begin{array}{l}\text { High INR, but already given anti-dote } \\
\text { vitamin K }\end{array}$ & $\begin{array}{l}\text { Include the prescription of the anti-dote vitamin } \mathrm{K} \text { into the } \\
\text { algorithm }\end{array}$ \\
\hline $\begin{array}{l}\text { Use of acetosal, dipyridamol, clopidogrel, } \\
\text { prasugrel without a HMG CoA-reduc- } \\
\text { tase inhibitor therapy (statin) }\end{array}$ & $\begin{array}{l}\text { Patients were considered too old of } \\
\text { age for HMG CoA-reductase inhibitor } \\
\text { therapy }\end{array}$ & $\begin{array}{l}\text { A frailty indicator might be considered for inclusion to deter- } \\
\text { mine if a HMG CoA-reductase inhibitor therapy should still be } \\
\text { prescribed }\end{array}$ \\
\hline
\end{tabular}

or involved reminders to evaluate the necessity of certain drugs. We classified these DRPs as relevant, since there was considerable doubt related to the chosen therapy. This might be interpreted differently in other studies.

\section{Further research}

Using automation to make medication reviews more efficient is considered highly necessary according to a recent survey (de Wit et al. 2014b). There remain several differences between CDSSs both content and efficiency of current CDSS varies considerably. Some CDSSs still rely on the manual input of a single patient's details such as medical history, medication and pathology. These CDSSs do support the medication review but are lacking in terms of time efficiency (de Wit et al. 2014a). The effectiveness of our CDSS to support medication reviews needs to be increased by 1) complementing the content with overlooked DRP strategies from the medication review and 2) by optimising the DRP notifications that were incorrectly assessed by the CDSS.

Furthermore, the results of this study show that certain DRP notifications are correct when strictly following the applicable guideline, but are found to be irrelevant after discussion in the gerontopharmacology meeting. The development of algorithms allowing discriminating between patients to initiate 'deprescribing' or to specifically not initiate pharmacotherapy treatment will be a challenge. Deprescribing aims to reduce the use of drugs that are less beneficial, or even, detrimental taking into account the individual needs for therapy (Scott et al. 2015). The challenge of incorporating 'deprescribing' is shown by the lack of DRP notifications in medication error type (b) 'medication without indication. An example of deprescribing and of not initiating pharmacotherapy treatment is the prescription of statins. In our study, treatment with HMG CoA-reductase inhibitor (statins) was not initiated in ten patients because they were too frail and too old. The benefit of stopping statins or not initiating statins when life expectancy is limited should be considered in CDSSs (Holmes and Todd 2015). The development of algorithms approaching the level of expertise in the gerontopharmacology meeting will be a great challenge and improvement for the CDSS.

\section{Conclusions}

Performing medication reviews in a hospitalised geriatric patient group can be of value seen the high number of accepted DRP strategies. More than half of the accepted DRP strategies were executed within 1 week. The distribution of the relevant medication error types shows the strengths and weaknesses of the CDSS compared to the manual medication review in this study. Our developed CDSS is currently unable to replace the manual medication review. It can however be of additional value for the manual medication review. Further development of the current CDSS is needed to fully support manual medication reviews.

\section{Abbreviations}

CDSS: clinical decision support system; DRPs: drug-related problems; ADR: adverse drug reactions; CPOE: computerised physician order entry; IGZ: Dutch Healthcare Inspectorate; KNMP: Royal Dutch Association for the Advancement of Pharmacy. 


\section{Authors' contributions}

All authors have participated to a sufficient extent to this study to be named as authors. HW, KH, MS, WS, RJ, HK, CMG have participated in the medication reviews (data acquiring). HW, KH, RJ, BW, HK, CMG, JS, WM, FV have participated in the interpretation of the data. All authors read and approved the final manuscript.

\section{Author details}

1 Department of Clinical Pharmacy and Toxicology, Zuyderland Medical Centre, Henri Dunantstraat 5, 6419 PC Heerlen, The Netherlands. ${ }^{2}$ Department of Internal Medicine, Section of Geriatric Medicine, Zuyderland Medical Centre, Sittard-Geleen, The Netherlands. ${ }^{3}$ Department of Clinical Pharmacy and Toxicology, Zuyderland Medical Centre, Sittard-Geleen, The Netherlands. ${ }^{4}$ Department of Methodology and Statistics, CAPHRI-School for Public Health and Primary Care, Maastricht University, Maastricht, The Netherlands. ${ }^{5}$ Department of Internal Medicine, Maastricht University Medical Centre, Maastricht, The Netherlands. ${ }^{6}$ Department of Psychiatry and Neuropsychology, Alzheimer Centrum Limburg/School for Mental Health and Neurosciences, Maastricht University, Maastricht, The Netherlands. ${ }^{7}$ Department of General Practice and Department of Health Services Research, CAPHRI-School for Public Health and Primary Care, Maastricht University, Maastricht, The Netherlands.

\section{Competing interests}

The authors declare that they have no competing interests

\section{Funding}

SCREEN-study supported by a grant from ZonMW (The Netherlands Organisation for Health Research and Development, Grant number 113101001)

Received: 9 December 2015 Accepted: 20 May 2016

Published online: 24 June 2016

\section{References}

Alldred DP, Raynor DK, Hughes C, Barber N, Chen TF, Spoor P (2013) Interventions to optimise prescribing for older people in care homes. Cochrane Database Syst Rev 2:CD009095

Blenkinsopp A, Bond C, Raynor DK (2012) Medication reviews. Br J Clin Pharmacol 74(4):573-580

Bright TJ, Wong A, Dhurjati R, Bristow E, Bastian L, Coeytaux RR, Samsa G, Hasselblad V, Williams JW, Musty MD, Wing L, Kendrick AS, Sanders GD, Lobach D (2012) Effect of clinical decision-support systems: a systematic review. Ann Intern Med 157(1):29-43

Christensen M, Lundh A (2013) Medication review in hospitalised patients to reduce morbidity and mortality. Cochrane Database Syst Rev 2:CD008986

Clegg A, Young J, Iliffe S, Rikkert MO, Rockwood K (2013) Frailty in elderly people. Lancet 381(9868):752-762

de Wit HAJM, Mestres Gonzalvo C, Hurkens KP, Mulder WJ, Janknegt R, Verhey FR, Schols JM, van derKuy PH (2013) Development of a computer system to support medication reviews in nursing homes. Int J Clin Pharm 35(5):668-672

de Wit HAJM, Mestres Gonzalvo C, Janknegt R, Schols JM, van der Kuy $\mathrm{PH}$ (2014a) A fully automated medication review? Int J Clin Pharm 36(2):220-221

de Wit HAJM, Winkens B, Mestres Gonzalvo C, Hurkens KPGM, Janknegt R, Schols JMGA, van der Kuy P-HM (2015) Clinical practice of medication reviews in institutional care settings for older people in the Netherlands: an explorative survey. Eur J Hosp Pharm 22:212-218

de Wit HAJM, Mestres Gonzalvo C, Cardenas J, Derijks HJ, Janknegt R, van der Kuy PH, Winkens B, Schols JM (2015) Evaluation of clinical rules in a standalone pharmacy based clinical decision support system for hospitalized and nursing home patients. Int J Med Inform 84(6):396-405

Eppenga WL, Derijks HJ, Conemans JM, Hermens WA, Wensing M, De Smet PA (2012) Comparison of a basic and an advanced pharmacotherapy-related clinical decision support system in a hospital care setting in the Netherlands. J Am Med Inform Assoc 19(1):66-71

Fraccaro P, Arguello Casteleiro M, Ainsworth J, Buchan I (2015) Adoption of clinical decision support in multimorbidity: a systematic review. JMIR Med Inform 3(1):e4
Hajjar ER, Cafiero AC, Hanlon JT (2007) Polypharmacy in elderly patients. Am J Geriatr Pharmacother 5(4):345-351

Herr M, Robine JM, Pinot J, Arvieu JJ, Ankri J (2015) Polypharmacy and frailty: prevalence, relationship, and impact on mortality in a French sample of 2350 old people. Pharmacoepidemiol Drug Saf 24(6):637-646

Holmes HM, Todd A (2015) Evidence-based deprescribing of statins in patients with advanced illness. JAMA Intern Med 175(5):701-702

Hurkens KPGM, Mestres-Gonzalvo C, de Wit HAJM, van der Kuy PHM, Janknegt R, FransVerhey, Schols JMGA, Stolk LML, Stehouwer CDA, Mulder W (2013) A survey on medication reviews in older patients: substantial variation in daily practice. J Gerontol Geriat Res 2:133. doi:10.4172/2167-7182.1000133

Jaspers MW, Smeulers M, Vermeulen H, Peute LW (2011) Effects of clinical decision-support systems on practitioner performance and patient outcomes: a synthesis of high-quality systematic review findings. J Am Med Inform Assoc 18(3):327-334

Kuperman GJ, Bobb A, Payne TH, Avery AJ, Gandhi TK, Burns G, Classen DC, Bates DW (2007) Medication-related clinical decision support in computerized provider order entry systems: a review. J Am Med Inform Assoc 14(1):29-40

Leendertse AJ, Egberts AC, Stoker LJ, van den Bemt PM, Group HS (2008) Frequency of and risk factors for preventable medication-related hospital admissions in the Netherlands. Arch Intern Med 168(17):1890-1896

Leendertse AJ, de Koning FH, Goudswaard AN, Jonkhoff AR, van den Bogert SC, de Gier HJ, Egberts TC, van den Bemt PM (2011) Preventing hospital admissions by reviewing medication (PHARM) in primary care: design of the cluster randomised, controlled, multi-centre PHARM-study. BMC Health Serv Res 11:4

Maher RL, Hanlon J, Hajjar ER (2014) Clinical consequences of polypharmacy in elderly. Expert Opin Drug Saf 13(1):57-65

Marasinghe KM (2015) Computerised clinical decision support systems to improve medication safety in long-term care homes: a systematic review. BMJ Open 5(5):e006539

Mestres Gonzalvo C, Hurkens KPGM, de Wit HAJM, van Oijen BPC, Janknegt R, Schols JMGA, Mulder WJ, Verhey FR, Winkens B, van der Kuy P-HM (2015) To what extent is clinical and laboratory information used to perform medication reviews in the nursing home setting? The CLEAR study. Ther Clin Risk Manag 11:767-777

Mestres C, Agustí A, Puerta L, Barba M (2015) Prescription of potentially inappropriate drugs for geriatric patients in long-term care: improvement through pharmacist's intervention. Eur J Hosp Pharm 22(4):198-201

Meulendijk MC, Spruit MR, Drenth-van Maanen AC, Numans ME, Brinkkemper S, Jansen PA, Knol W (2015) Computerized decision support improves medication review effectiveness: an experiment evaluating the strip assistant's usability. Drugs Aging 32(6):495-503

Nobili A, Licata G, Salerno F, Pasina L, Tettamanti M, Franchi C, De Vittorio L, Marengoni A, Corrao S, lorio A, Marcucci M, Mannucci PM, Investigators S (2011) Polypharmacy, length of hospital stay, and in-hospital mortality among elderly patients in internal medicine wards. The REPOSI study. Eur J Clin Pharmacol 67(5):507-519

O'Sullivan D, O'Mahony D, O'Connor MN, Gallagher P, Cullinan S, O'Sullivan R, Gallagher J, Eustace J, Byrne S (2014) The impact of a structured pharmacist intervention on the appropriateness of prescribing in older hospitalized patients. Drugs Aging 31(6):471-481

Ranji SR, Rennke S, Wachter RM (2014) Computerised provider order entry combined with clinical decision support systems to improve medication safety: a narrative review. BMJ Qual Saf 23(9):773-780

Richtlijn elektronisch voorschrijven (2013) [internet]. [Cited 20 September 2016]. Available from: http://knmg.artsennet.nl/Publicaties/KNMGpublicatie/136411/Richtlijn-elektronisch-voorschrijven-2013.htm

Rommers MK, Teepe-Twiss IM, Guchelaar HJ (2011) A computerized adverse drug event alerting system using clinical rules: a retrospective and prospective comparison with conventional medication surveillance in the Netherlands. Drug Saf 34(3):233-242

Schols JM, Crebolder HF, van Weel C (2004) Nursing home and nursing home physician: the Dutch experience. J Am Med Dir Assoc 5(3):207-212

Scott IA, Hilmer SN, Reeve E, Potter K, Le Couteur D, Rigby D, Gnjidic D, Del Mar CB, Roughead EE, Page A, Jansen J, Martin JH (2015) Reducing inappropriate polypharmacy: the process of deprescribing. JAMA Intern Med 175(5):827-834 
Silva C, Ramalho C, Luz I, Monteiro J, Fresco P (2015) Drug-related problems in institutionalized, polymedicated elderly patients: opportunities for pharmacist intervention. Int J Clin Pharm 37(2):327-334

Tawadrous D, Shariff SZ, Haynes RB, lansavichus AV, Jain AK, Garg AX (2011) Use of clinical decision support systems for kidney-related drug prescribing: a systematic review. Am J Kidney Dis 58(6):903-914

van der Sijs H, Aarts J, Vulto A, Berg M (2006) Overriding of drug safety alerts in computerized physician order entry. J Am Med Inform Assoc 13(2):138-147

van Dijk KN, van Asselt DZ, Vogel D, van der Hooft CS, Van Roon EN, Brouwers $J R$ (2009) Effects of a structured medication review by geriatrician and clinical pharmacologist on appropriateness of pharmacotherapy in frail elderly inpatients. Tijdschr Gerontol Geriatr 40(2):72-78
Verrue CL, Petrovic M, Mehuys E, Remon JP, Vander Stichele R (2009) Pharmacists' interventions for optimization of medication use in nursing homes: a systematic review. Drugs Aging 26(1):37-49

Wallerstedt SM, Kindblom JM, Nylen K, Samuelsson O, Strandell A (2014) Medication reviews for nursing home residents to reduce mortality and hospitalization: systematic review and meta-analysis. Br J Clin Pharmacol 78(3):488-497

\section{Submit your manuscript to a SpringerOpen ${ }^{\circ}$ journal and benefit from:}

- Convenient online submission

- Rigorous peer review

- Immediate publication on acceptance

- Open access: articles freely available online

- High visibility within the field

- Retaining the copyright to your article 